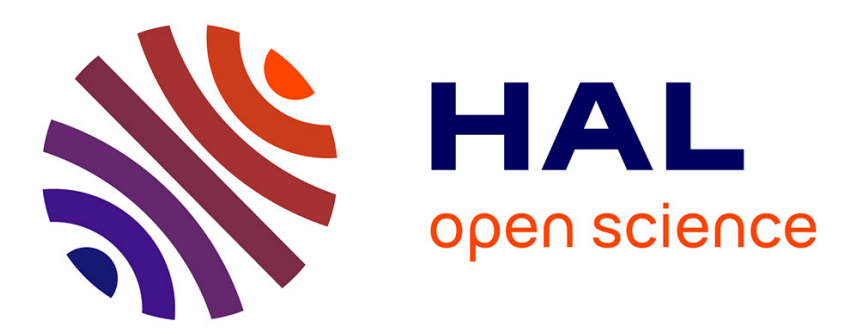

\title{
Quantification of soil volumes in the Eg\&Bt-horizon of an Albeluvisol using image analysis
}

David Montagne, Isabelle Cousin, Lydie Le Forestier, Joël Daroussin, Sophie Cornu

\section{- To cite this version:}

David Montagne, Isabelle Cousin, Lydie Le Forestier, Joël Daroussin, Sophie Cornu. Quantification of soil volumes in the Eg\&Bt-horizon of an Albeluvisol using image analysis. Canadian Journal of Soil Science, 2007, 87, pp.51-59. hal-00103973

\section{HAL Id: hal-00103973 \\ https://hal-insu.archives-ouvertes.fr/hal-00103973}

Submitted on 5 Oct 2006

HAL is a multi-disciplinary open access archive for the deposit and dissemination of scientific research documents, whether they are published or not. The documents may come from teaching and research institutions in France or abroad, or from public or private research centers.
L'archive ouverte pluridisciplinaire HAL, est destinée au dépôt et à la diffusion de documents scientifiques de niveau recherche, publiés ou non, émanant des établissements d'enseignement et de recherche français ou étrangers, des laboratoires publics ou privés. 


\section{Quantification of soil volumes in the Eg\&Bt-horizon of an}

\section{Albeluvisol using image analysis}

David Montagne $^{\mathrm{a}^{*}}$, Isabelle Cousin ${ }^{\mathrm{a}}$, Lydie Le Forestier ${ }^{\mathrm{b}}$, Joël Daroussin ${ }^{\mathrm{a}}$, Sophie Cornu ${ }^{\mathrm{a}}$

${ }^{a}$ Unité de recherche en Science du Sol, INRA Orléans, avenue de la Pomme de Pin, BP 20619, 45166 Olivet cedex, France

b ISTO (UMR 6113), Polytech’Orléans, 8 rue Léonard de Vinci, 45072 Orléans cedex 2, France

* Corresponding author

Phone : +33238417845

Fax : +33238417869

E-mail : David.Montagne@orleans.inra.fr

Keywords: pedogenesis, drainage, image analysis, Albeluvisol, Representative Elementary Volume (REV). 


\begin{abstract}
In this study, we provide a strategy to quantify the effects on soil evolution of driving forces such as human activities or global change. This strategy was developed for situations in which soil evolution resulted in the formation of a complex juxtaposition of soil volumes with distinct properties including soil colours. It is based on image analysis. Our approach proceeds in two steps: (1) to find the minimum sample size over which the soil anisotropy can be neglected and (2) to define a Representative Elementary Volume (REV) of that sample. This approach was developed on the Eg\&Bt horizon of a drained Albeluvisol in which three decimetric soil monoliths were sampled at 60, 110 and $210 \mathrm{~cm}$ from a drain. The monoliths were sliced in $1.5 \mathrm{~cm}$ horizontal layers. Each slice was photographed and studied by image analysis. At the monolith scale, there was neither lateral nor vertical anisotropy. The sampled monoliths were larger than the REV allowing quantification of the different soil volumes constituting this particular horizon. We quantified significant evolutions of the abundance of the different soil volumes characterized by their colour as a function of the distance to the drain. Such a quantification of the effects on soil evolution of human activities or global change equally applies for Podzols, Calcisols or Gleysols for which pedogenesis also resulted in contrasted soil colour evolutions.
\end{abstract}




\section{RESUME}

Dans cette étude, nous proposons une méthode de quantification par analyse d'image de l'évolution récente des sols dans des situations où la pédogenèse a conduit à l'individualisation de volumes de sol aux propriétés contrastées, notamment par leur couleur. Ce travail repose sur la recherche (1) d'un volume de sol pour lequel il n'existe pas d'anisotropie nette de l'abondance des différents volumes de sol définis par leur couleur; (2) du Volume Elémentaire Représentatif (VER) de chacun des volumes de sol caractérisé par sa couleur. Cette méthode a été testée sur l’horizon Eg\&Bt d'un Albeluvisol drainé. Cet horizon est en effet constitué de plusieurs volumes de sol aux couleurs très contrastées et dont les abondances relatives évoluent en fonction des conditions hydrodynamiques locales.

Trois monolithes pluri-centimétriques ont été échantillonnés à 60, 110 et 210 cm d'un drain, puis découpés verticalement en couches (de 1,5 cm d'épaisseur), dont les surfaces ont été photographiées et analysées par traitement d’image.

A l'échelle du monolithe, il n’y a pas de gradient latéral et vertical de la répartition des volumes pédologiques. La taille des monolithes est supérieure à celle du VER, permettant une quantification des différents volumes pédologiques. Il a alors été possible de quantifier les évolutions de l'abondance des différents volumes pédologiques en fonction de la distance au drain. De telles quantifications de l'évolution des sols peuvent être envisagées dans les sols au sein desquels la pédogenèse provoque des évolutions de couleurs comme par exemple dans les Podzols, les Calcisols ou les Gleysols. 


\section{INTRODUCTION}

Soil evolution results from the progressive transformations under continuous fluxes of matter and energy of primary minerals from the parent material into more stable secondary phases (Chadwick and Chorover, 2001). Human activities and climate change are known to affect pedogenesis by modifying these fluxes (see White and Blum, 1995 for an example of the climate impact). Their consequences on pedogenesis are however poorly known and rarely quantified.

In several cases, pedogenesis results in the formation of a complex juxtaposition of soil volumes with distinct properties including colour. It is for example the case for (i), Podzols and Albeluvisols in which tongues of albic soil material developed into a horizon of higher chroma in colour; (ii) Calcisol, where uneven precipitation of calcite developed in the soil matrix of calcic and petrocalcic horizons; and (iii) Gleysols and other waterlogged soils that present a colour pattern made up of reddish to yellowish colours in combination with greyish to bluish ones. These four soil groups represent $18.5 \%$ of the world soil resources (Dreissen et al., 2001). To quantify the evolution of such soils in response to human activities or climate change, it is necessary to quantify the changes in the relative abundances of the different soil volumes. Such quantifications are generally not performed except maybe through expertise on a pit surface. It could however be quantified on the basis of their distinctive colour using image analysis, the latter being one of the most important diagnostic parameters in field pedology. Indeed, some diagnostic horizons such as the albic one, are mainly determined on the basis of their colour (Deckers et al., 1998). This study aims at providing a strategy to quantify the soil evolution in terms of the relative abundance of the different soil volumes characterised by distinctive colours using image analysis.

Our approach consists of two steps: (1) to find the sample of minimum size over which the human or climate induced heterogeneity can be neglected, and (2) to define, on that 
sample, a Representative Elementary Volume (REV) for each particular soil volume characterized by its colour.

We tested this approach on a drained Albeluvisol considering drainage as an example of human-induced perturbation of the water fluxes through soils (Skaggs et al., 1994). Indeed, the relative amount of the bleached tongues and of the clayey and ochre residual soil volumes characterising Albeluvisols evolves in space according to the local hydrodynamic conditions (Nicole et al., 2003). The ability of our approach to quantify (1) the different soil volumes of the studied Albeluvisol and (2) their variation in abundance along a trench perpendicular to a drain was estimated. 


\section{MATERIAL AND METHODS}

\section{Studied site and soil}

The study site is located on the Yonne plateau (France) consisting of quaternary loamy deposits overlying clay ones. On the crest, Albeluvisols (Dreissen et al., 2001) have developed. They are generally cropped and artificially drained.

The studied Albeluvisol comprises five horizons:

- From 0 to 25 (30) $\mathrm{cm}$ of depth, a silty, brown to grey, A-horizon containing many degraded organic fragments.

- From 25 to 35 (40) cm of depth, a silty E-horizon whose colour is greyer than the upper A-horizon (10YR6/4).

- From 35 to 60 (70) $\mathrm{cm}$ of depth, a Eg\&Bt-horizon that is characterised by the juxtaposition of different types of soil volumes. The most abundant volumes are white-grey (10YR8/2 to 10YR7/1) to pale-brown (10YR7/4) and silty. The less abundant ones are of decimetric size, ochre colour (10YR5/6 to 10YR5/8) and clayey. In the middle of these last volumes, black concretions and impregnations are observed. The ochre, clayey volumes, including concretions and impregnations, are interpreted as residual volumes inherited from the degradation of the underlying horizon.

- From 60 to 90 (105) $\mathrm{cm}$ of depth, a Btgd-horizon exhibits a juxtaposition of the previously described soil volumes, the most abundant being the ochre ones. The grey-white to pale-brown soil volumes differ slightly in colour from the upper ones (10YR7/1 to 10YR8/2) and are present as glosses, with, in places, 
small volumes of grey-blue to brown-salmon clay rich volumes. Black impregnations are abundant.

- From 90 to $115 \mathrm{~cm}$ of depth, a clay-rich B3-horizon, comprised of 80 \% clayrich ochre volumes associated with centimetric grey-blue clayey glosses.

In the studied plot, the drainage system was installed by subsoiling in 1988 that is 16 years before the present study. Drains are located at $1 \mathrm{~m}$ depth within the Btgd horizon and spaced 15 m apart.

A 3 meter long trench was dug perpendicularly to a drain in a x,z-plane (Figure 1). Lateral gradients were observed along the x-direction of this trench: moving towards the drain, the amount of the silty white-grey volumes increased until reaching the zone disturbed by subsoiling. Conversely, the amount of the clayey ochre volumes decreased. This was particularly clear in the Eg\&Bt horizon (Figure 1). In addition, the amount of white-grey and ochre volumes varied along the z-axis, i.e. with depth, due to the development of the horizonation. On the opposite, no macroscopic anisotropy in the amount of the different soil volumes was observed along the y-axis, i.e. along the drain.

\section{Justification of the sampling procedure}

According to field observations, the amount of the different soil volumes varied 1) laterally along the x-axis, on a pluri-metric scale, and 2) vertically, along the z-axis, on a pluri-decimetric scale. Due to these two superimposed evolutions, it was not possible to analyse the lateral evolution through image analysis of the trench face. Indeed, to be representative, the analysis has to be performed perpendicularly to the evolution gradient. 
As we were interested in quantifying the lateral evolution, developed on a pluri-metric scale, we decided to sample decimetric soil monoliths at three distances from the drain, i.e. perpendicular to the main anisotropy axis at this scale.

In addition, macroscopic observations in the field suggested that, at the monolith scale, the anisotropy due to pedological differentiation as glosses, along the z-direction, was more important than the anisotropy due to drainage, along the x-direction. The serial sections were therefore realised in $\mathrm{x}, \mathrm{y}$-planes, perpendicular to the main anisotropy axis at the monolith scale.

\section{Field sampling procedure and image analysis}

Three soil monoliths of size $\mathrm{x}=27 \mathrm{~cm}, \mathrm{y}=17 \mathrm{~cm}$ and $\mathrm{z}=12 \mathrm{~cm}$ were sampled in the Eg\&Bt-horizon at 60, 110 and $210 \mathrm{~cm}$ of the drain (Figure 1) and at $395 \mathrm{~mm}$ depth. The position at $210 \mathrm{~cm}$ from the drain was considered as the reference position. For convenience, these monoliths were named monolith 60, monolith 110 and monolith 210 . The sampling was realised in autumn, after the soil was rewetted by rains. The water content in the soil at sampling time was $15 \mathrm{~g} 100 \mathrm{~g}^{-1}$. Immediately after sampling, the monoliths were kept in plastic boxes hermetically closed and were frozen to avoid drying and disturbance by soil fauna.

At the beginning of the experiment, the monoliths were gently unfrozen and placed at laboratory temperature. The surface of each monolith (in a x,y-plane) was photographed in colour (RGB mode) using natural light. A $1.5 \mathrm{~cm}$ slice from the monolith surface was then cut off with a knife. The new face was then photographed again. This was repeated over the whole monolith thickness (Figure 2). In order to compare all the pictures, lighting conditions and water content had to be kept constant. Lighting conditions changes were limited by maintaining similar exposure conditions for all the pictures. To keep the water content as constant as possible, the surface of the monolith was regularly and gently rewetted by 
sprinkling and the box was closed again hermetically between two cuts, keeping a wet piece of sponge cloth on the upper side of the monolith.

At the end of the experiment, 7 to 8 RGB pictures were obtained depending on the monolith, with a resolution of $180 \mu \mathrm{m}$ per pixel. To avoid border effects, a $260 \mathrm{~cm}^{2}$ surface area (about $22 \times 12 \mathrm{~cm}^{2}$ ), located in the middle of the pictures, was studied.

The image analysis was achieved using the ERDAS IMAGINE ${ }^{\mathrm{TM}}$ version 8.7 image processing commercial software package. The images were classified in order to distinguish the different soil volumes and to obtain well defined distinct objects. The target classes being known, classification was based on a supervised method. For each monolith, one picture was selected for training. From that we manually selected pixels in the 3-dimensional space defined by the Red, Green and Blue channels that were clearly representative of the different soil volumes thus defining a spectral signature and corresponding class for each soil volume. Based on these signatures, every pixel in every image for that monolith was then automatically allocated to the best corresponding class by applying the maximum likelihood parametric decision rule. An advantage of the method is that no pixel remains unclassified. From the classified image, surface areas for each soil volume could easily be computed through pixel counts. Finally integrated results over all the images were calculated.

\section{Data analysis}

In order to verify that the sampling of the monoliths was correct, one has first to check that the monoliths were small enough to neglect (1) the heterogeneity induced by drainage and 2) the heterogeneity induced by pedological differentiation as glosses.

Lateral gradients within the monoliths along the $\mathrm{x}$-direction (respectively $\mathrm{y}$-direction) were researched by dividing the pictures in bands of $1.8 \mathrm{~cm}$ parallel (respectively perpendicular) to the drain axis, in the $\mathrm{y}$ - (respectively $\mathrm{x}$-) direction. The areas of the different soil volumes were measured on each image. Integrated results over all the images were then 
calculated. ANOVA at a $5 \%$ confidence level (Tukey tests) were performed in order to identify significant differences in the relative abundance of the different soil volumes among the bands.

Vertical heterogeneity at each sampling position was assessed by analysing the evolution of the abundance of the soil volumes by performing an ANOVA at a $5 \%$ confidence level (Tukey tests) among the eight images of increasing depth, each of them being characterised by the quantifications obtained on the bands of $1.8 \mathrm{~cm}$ parallel to the drain axis.

Once confirmed that the monoliths did not exhibit any intra variability, we verified that the monolith size was large enough to correctly represent each soil volume. In other words, we looked for the Representative Elementary Volume (REV) of each soil volume on each image. Indeed, one usually assumes that the studied sample, a subportion of the studied system, is representative of the whole system, which means that the sample is a representative elementary volume of the considered system. As far as homogeneous objects are concerned, the REV is well defined: it is simply the minimum size of the object above which the characteristic property of the object is constant for whatever sample size is considered (Bear 1972). Determination of the REV was then realised in our images by measuring the area of the different soil volumes within square windows of increasing size centered in the images. At each step, the size of the test window was increased by ten pixels, i.e. $1.8 \mathrm{~mm}$ on every side (left, right, top and bottom sides). The test windows thus ranged from $0.14 \mathrm{~cm}^{2}$ to $260 \mathrm{~cm}^{2}$.

Finally, to discuss the effect of drainage on the evolution of the Eg\&Bt-horizon, an ANOVA at a $5 \%$ confidence level (Tukey tests) was performed on the measurements of each soil volume. 


\section{RESULTS AND DISCUSSION}

\section{Local heterogeneity of the monoliths}

Lateral variation of the relative abundance of the soil volumes along the y-axis

From the macroscopic observation on the trench, we hypothesised that there was no gradient along the y-axis, i.e. parallel to the drain. In order to verify this hypothesis, figure 3.a reports for monolith 210, the evolution of the relative abundance of the different soil volumes by bands of $1.8 \mathrm{~cm}$ integrated on the whole monolith thickness. According to the ANOVA no significant difference among the different bands was observed for any of the soil volumes, whatever the considered monolith. Consequently, there is no gradient along the y-axis and the initial hypothesis is verified.

Lateral variation of the relative abundance of the soil volumes along the x-axis

In a similar manner, Figure 3.b presents for monolith 210, the intra-monolith variability along the $\mathrm{x}$-axis of the relative amount of the different soil volumes integrated on the whole monolith thickness. There again, the amount of each soil volume did not vary significantly among the bands according to the results of the ANOVA. Whatever the considered monolith, no gradient were observed in the x-direction. One can therefore conclude that the anisotropy induced by drainage which could visually be observed at the trench scale can be neglected at the monolith scale.

Vertical variation of the relative abundance of the soil volumes along the z-axis.

The evolution of abundance of the soil volumes among the seven images is presented in figure 3.c for monolith 210. The corresponding ANOVA is reported in Table 1 and in Tables 2 and 3 for respectively monolith 110 and 60. Contrary to directions $\mathrm{x}$ and y discussed above, significant differences of the relative amounts of the different soil volumes were 
observed as a function of depth (Table 1). This agrees with visual observations suggesting that, at the monolith scale, the heterogeneity along the $\mathrm{z}$-direction was more important than the heterogeneity in the $\mathrm{x}$ - and $\mathrm{y}$-directions. The heterogeneity was however not organised as a function of depth. As an example, the relative amounts of the pale-brown soil volumes at $395 \mathrm{~mm}$ and $500 \mathrm{~mm}$ of depth were not significantly different whereas they were significantly lower than those at depths of 425 and $440 \mathrm{~mm}$. Similar results were observed for monoliths 60 and 110 (Tables 2 and 3).

At the monolith scale and for all three studied monoliths, no anisotropy was observed as a function of depth, i.e. induced by tonguing.

Finally, the sampled monoliths did not exhibit any anisotropy in the relative amount of the different soil volumes, whatever the considered direction.

\section{Research on a REV for each soil volume}

As the monoliths did not exhibit any intra variability, we looked for the REV for each soil volume. Figure 4 reports the relative amount of each soil volume for a test image of monolith 210 as a function of size of the test area. Whatever the soil volume, one can observe that its relative abundance varied with the size of the analysed window but tended towards stabilisation for large windows. The white-grey volumes covers $4.4 \%$ of the entire image, the pale-brown ones $33.8 \%$, the ochre ones $57.6 \%$ and the black ones $4.2 \%$ (Figure 4 ). After the image analysis presented on figure 4 for monolith 210, the relative abundance stabilised when the window size reached $250 \mathrm{~cm}^{2}, 240 \mathrm{~cm}^{2}, 100 \mathrm{~cm}^{2}$ and $220 \mathrm{~cm}^{2}$ for the white-grey, palebrown, ochre and black volumes respectively. Analysing all other images from all other monoliths, these stabilisation levels varied slightly but were of the same order of magnitude as for the image presented here. As a stabilization level can generally be found, the sampled monoliths were larger than the REV and thus of sufficient size as far as the quantification of 
the different soil volumes was concerned. As a consequence, the evolution of the abundance in soil volumes along the $\mathrm{x}$-axis could be quantified.

\section{Quantification of the evolution of the abundance in soil volumes along the} x-axis

Figure 5 reports the relative abundance of the four soil volumes for each monolith and the associated ANOVA. The white-grey and pale-brown volumes represented $45 \%$ of the total image at $210 \mathrm{~cm}$ from the drain and about $65 \%$ at $60 \mathrm{~cm}$. Monolith 110 was not significantly different from the other two monoliths as it exhibited an intermediary situation. As the distance to the drain decreased, the abundance of the white-grey, the pale-brown and the black volumes increased while the abundance of the ochre volumes decreased. These evolutions were significant between monoliths 60 and 210. They can be interpreted as the influence of drainage on the Albeluvisol pedogenesis: the installation of the drainage network, 16 years ago, led to a $15 \%$ decrease in the abundance of the ochre volumes. 


\section{CONCLUSION}

Image analysis of soil monoliths enabled quantification of the changes in the relative abundance of soil volumes and thus of the effects on the evolution of such soil due to human activities or climate change. We determined that the abundance of the ochre soil volumes decreased by about 15\% due to the installation of the drainage network, 16 years ago, corresponding to an average of $1 \%$ per year. As shown by this study, our approach is a powerful tool to quantify the intensity and the velocity of pedogenesis. Although it is restricted to situations in which pedogenesis results in the formation of a complex juxtaposition of soil volumes with clearly distinct colours, the method remains interesting in a context in which quantitative data on soil evolution are extremely rare.

The developed method, based on image analysis on serial sections, enabled us to quantitatively determine that, at the scale of the monolith, the lateral and the vertical anisotropy can be neglected. This monolith size was, however, large enough to define a REV for each of the identified soil volumes. The developed protocol may seem heavy and time consuming. However, we would like to stress the point that the determination of the REV should be a prerequisite for all the experimental studies. Its knowledge is indeed essential in order to insure that the obtained results can be generalised and to allow relevant conclusions, especially in the context of the characterisation of heterogeneous, anisotropic or multi-scale systems.

Finally, in the studied case, the abundance of the soil volumes varied both laterally under the influence of drainage, and vertically as induced by horizon differentiation such as glosses. We demonstrated however that the lateral variability induced by drainage observed at 
the meter scale was not present at the decimetric scale of the monolith which was isotropic. It thus clearly illustrates the organization of soils at several nested scales. 


\section{AKNOWLEDGMENTS}

This work was funded by the Région Centre. The authors also gratefully acknowledge C. Le Lay and O. Josière for technical assistance during the field sampling and laboratory experiment, S. Desbourdes for figure design, and Dr. J.P. Lamarche of the Department of applied mathematics of the University of Orléans for his advice on statistical analysis. Finally, the authors thank the anonymous reviewers for their help in improving the clarity of the manuscript and the American Journal Experts association for english editing.

\section{LITERATURE}

Bear J., 1972. Dynamics of fluids in porous media. Elsevier, New York

Chadwick O.A., Chorover J., 2001. The Chemistry of pedogenic tresholds, Geoderma 100: 321-353.

Deckers J.A., Spaargaren O.C., Nactergaele F.O., Oldeman L.R., Brinkman R. (Editors), 1998. World Reference Base for Soil Resources. World soil resources reports n84. FAO-ISRIC-AISS, Rome, Italia.

Dreissen P., Deckers J., Spaargaren O., Nachtergaele F. (Editors), 2001. Lectures Notes on the Major Soils of the World, World soil resources reports n 94. FAO, Rome, Italia.

Nicole J., Coquet Y., Vachier P., Michelin J., Dever L., 2003. Fonctionnement hydrodynamique et différenciation pédologique d'une couverture de sols limoneux hydromorphes en Bassin Parisien, Etude et Gestion des Sols, 10: 173-190.

Skaggs R.W., Breve M.A., Gilliam J.W., 1994. Hydrologic and water quality impact of agricultural drainage, Critical Reviews in Environmental Science and Technology, 24: 1-32. 
White F., Blum A.E., 1995. Effects of climate on chemical weathering in watersheds, Geochimica and Cosmochimica Acta 59: 1729-1747. 
Table 1: Results of an ANOVA (Tukey tests) at $5 \%$ level of confidence for the monolith sampled at $210 \mathrm{~cm}$ from the drain. The relative amounts of each soil volume are compared among the different depths (z-axis). Within a column, different letters between 2 lines indicates a significant difference in the amount at the $5 \%$ level with $\mathrm{A}<\mathrm{B}<\mathrm{C}$.

\begin{tabular}{|c|c|c|c|c|}
\hline Depth (mm) & White-Grey & Pale-Brown & Ochre & Black \\
\hline 395 & A & A & BC & A \\
\hline 410 & A & A & C & AB \\
\hline 425 & B & B & A & B \\
\hline 440 & B & B & A & B \\
\hline 470 & AB & A & C & A \\
\hline 485 & AB & A & BC & AB \\
\hline 500 & B & A & B & AB \\
\hline
\end{tabular}


Table 2: Results of an ANOVA (Tukey tests) at $5 \%$ level of confidence for the monolith sampled at $110 \mathrm{~cm}$ from the drain. The relative amounts of each soil volume are compared among the different depths (z-axis). Within a column, different letters between 2 lines indicates a significant difference in the amount at the $5 \%$ level with $\mathrm{A}<\mathrm{B}<\mathrm{C}$.

\begin{tabular}{|c|c|c|c|c|}
\hline Depth (mm) & White-Grey & Pale-Brown & Ochre & Black \\
\hline 375 & $\mathrm{~A}$ & $\mathrm{C}$ & $\mathrm{A}$ & $\mathrm{AB}$ \\
\hline 390 & $\mathrm{~B}$ & $\mathrm{AB}$ & $\mathrm{A}$ & $\mathrm{B}$ \\
\hline 405 & $\mathrm{~A}$ & $\mathrm{C}$ & $\mathrm{A}$ & $\mathrm{AB}$ \\
\hline 420 & $\mathrm{~A}$ & $\mathrm{C}$ & $\mathrm{AB}$ & $\mathrm{A}$ \\
\hline 435 & $\mathrm{~A}$ & $\mathrm{BC}$ & $\mathrm{AB}$ & $\mathrm{AB}$ \\
\hline 480 & $\mathrm{~A}$ & $\mathrm{~A}$ & $\mathrm{~B}$ & $\mathrm{AB}$ \\
\hline
\end{tabular}


Table 3: Results of an ANOVA (Tukey tests) at $5 \%$ level of confidence for the monolith sampled at $60 \mathrm{~cm}$ from the drain. The relative amounts of each soil volume are compared among the different depths (z-axis). Within a column, different letters between 2 lines indicates a significant difference in the amount at the $5 \%$ level with $\mathrm{A}<\mathrm{B}<\mathrm{C}$.

\begin{tabular}{|c|c|c|c|c|}
\hline Depth (mm) & White-Grey & Pale-Brown & Ochre & Black \\
\hline 455 & $\mathrm{~A}$ & $\mathrm{~A}$ & $\mathrm{~B}$ & $\mathrm{~B}$ \\
\hline 470 & $\mathrm{BC}$ & $\mathrm{BC}$ & $\mathrm{A}$ & $\mathrm{B}$ \\
\hline 485 & $\mathrm{AB}$ & $\mathrm{BC}$ & $\mathrm{A}$ & $\mathrm{B}$ \\
\hline 500 & $\mathrm{C}$ & $\mathrm{BC}$ & $\mathrm{A}$ & $\mathrm{AB}$ \\
\hline 515 & $\mathrm{BC}$ & $\mathrm{C}$ & $\mathrm{A}$ & $\mathrm{AB}$ \\
\hline 530 & $\mathrm{AB}$ & $\mathrm{AB}$ & $\mathrm{B}$ & $\mathrm{A}$ \\
\hline
\end{tabular}




\section{Figure captions}

Figure 1: a: Picture of the studied profile onto which the drain, the zone perturbed by subsoiling and the sampled monoliths are located, b: details of a monolith sampling onto which the 4 different soil volumes are labelled.

Figure 2: Serial sectioning method for quantification of the soil volumes.

Figure 3: Intra-monolith variability of the relative amount of the different soil volumes in the monolith sampled at $210 \mathrm{~cm}$ from the drain along. a: the y-axis (moving parallel to the drain); $\mathrm{b}$ : along the $\mathrm{x}$-axis (moving away from the drain) and $\mathrm{c}$ : along the $\mathrm{z}$ axis (moving deeper down the profile). For a and b, data are integrated values calculated on 7 pictures.

Figure 4: Evolution of the relative amount of the different soil volumes in the monolith sampled at $210 \mathrm{~cm}$ from the drain as a function of the increasing analyzed area of the image. Dotted lines represent $\mathrm{REV} \pm 5 \%$. Black lines represent $\mathrm{REV} \pm 10 \%$.

Figure 5: Relative amount of each soil volume in each monolith. a, and, b: results of an ANOVA at $5 \%$ level of confidence (Tukey tests) to compare the relative abundance of the different soil volumes among the three monoliths. 
Figure 1

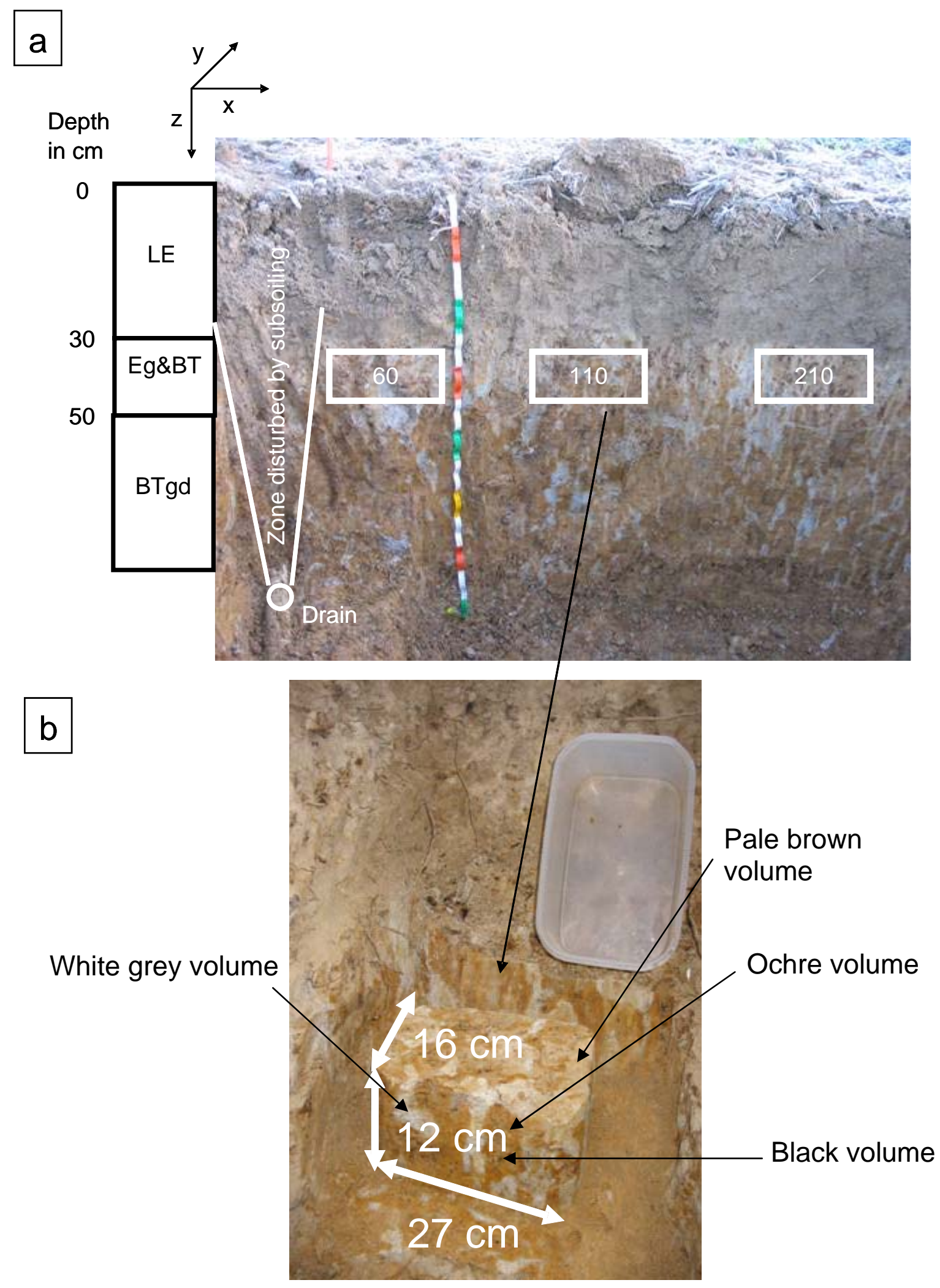


Figure 2

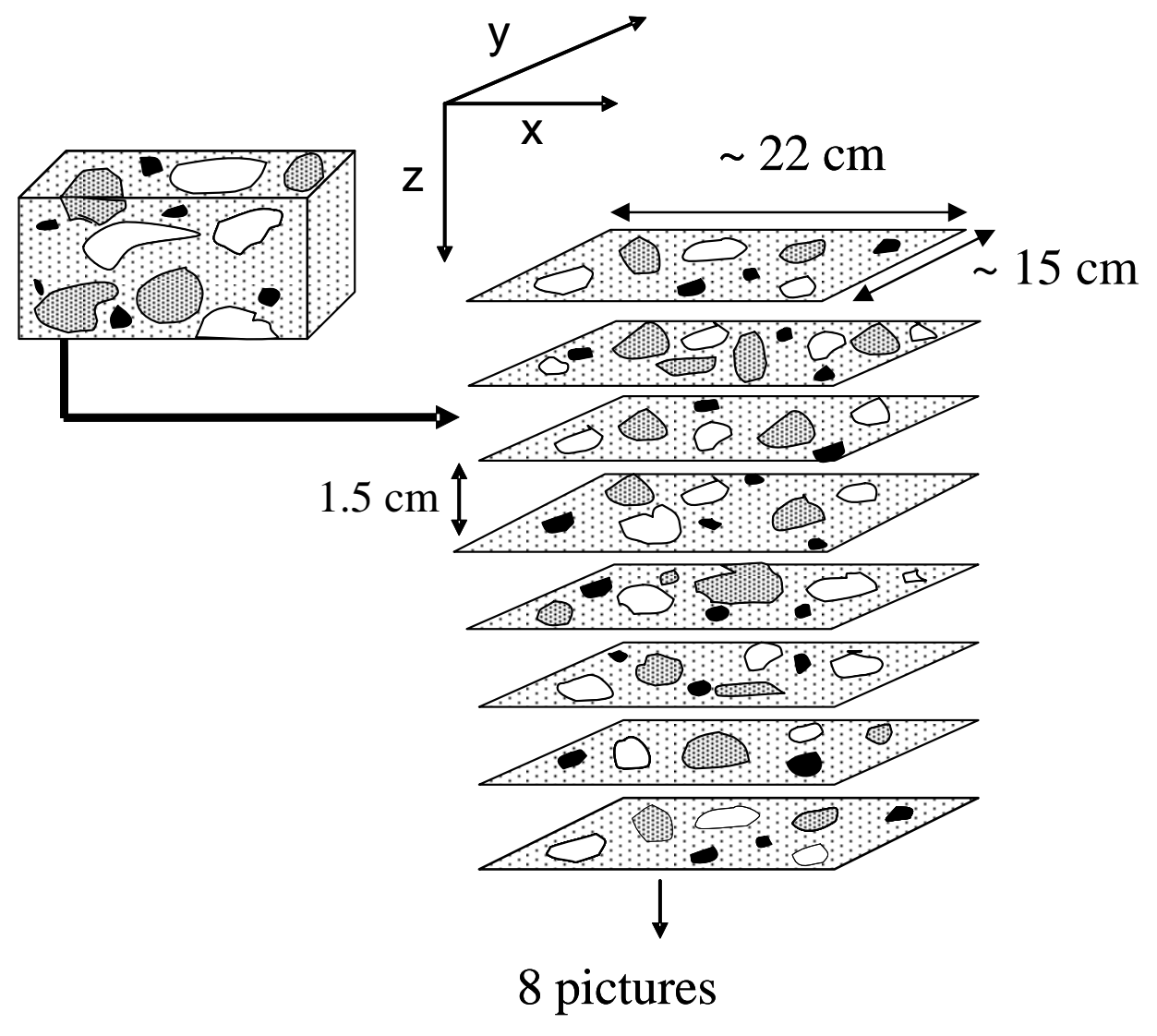

1 pixel $=180 \mu \mathrm{m} \times 180 \mu \mathrm{m}$

Image analysis

$\square$ White-grey volumes

레.: Ochre volumes

Pale-brown volumes

Black volumes 
Figure 3
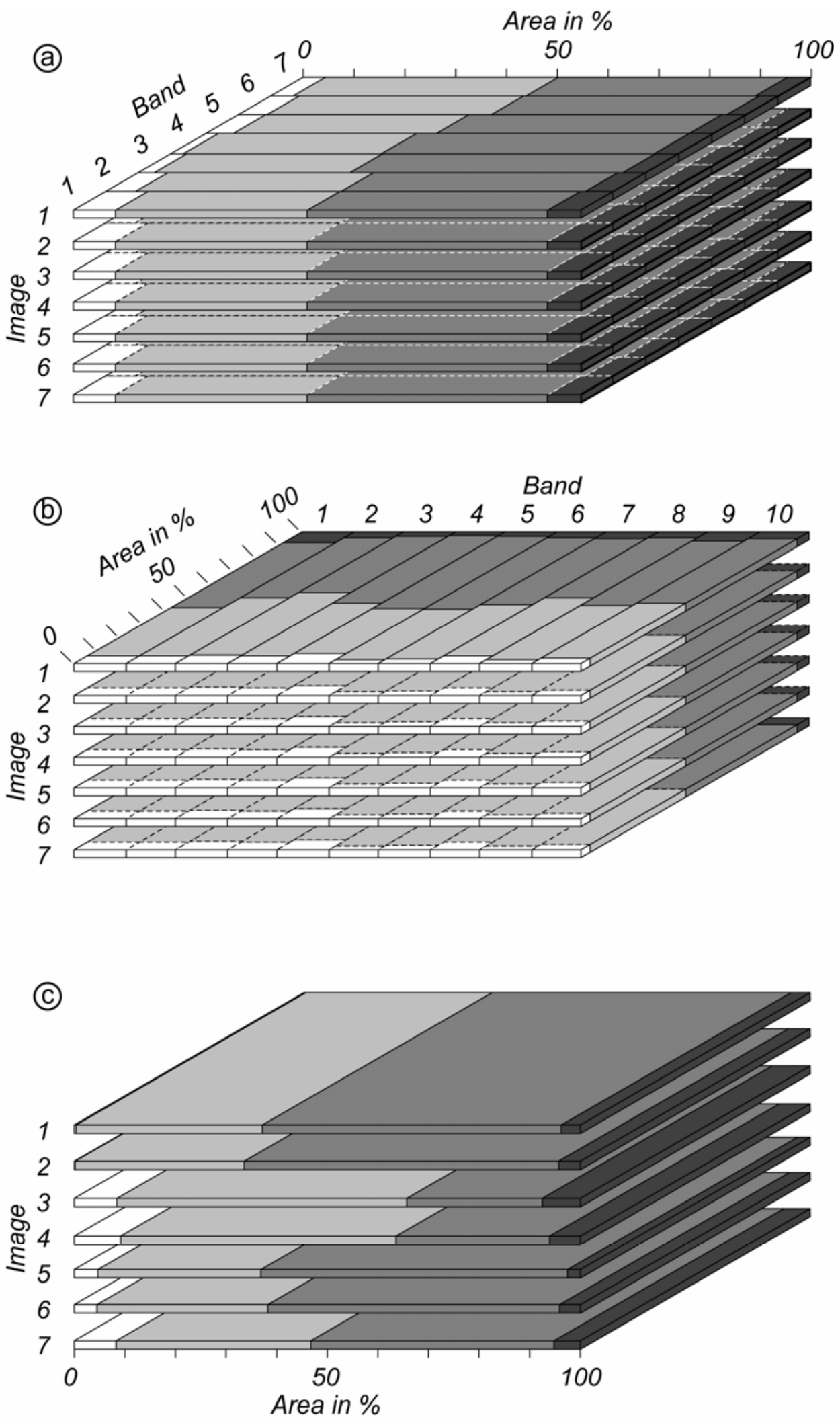

White-grey volumes

Ochre volumes

Pale-brown volumes

Black volumes 
Figure 4
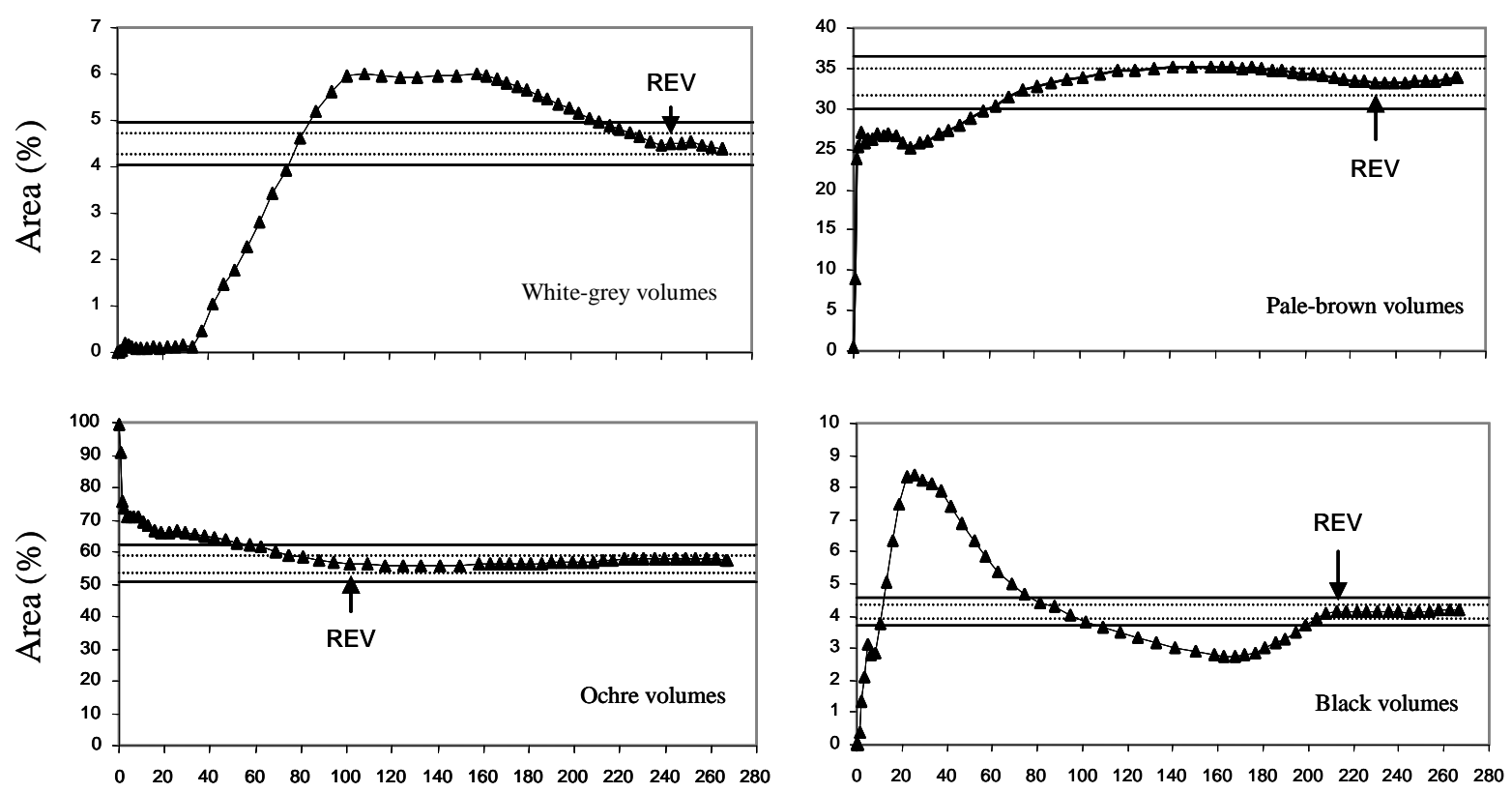

Size of the analyzed image in $\mathrm{cm}^{2}$

Size of the analyzed image in $\mathrm{cm}^{2}$ 
Figure 5
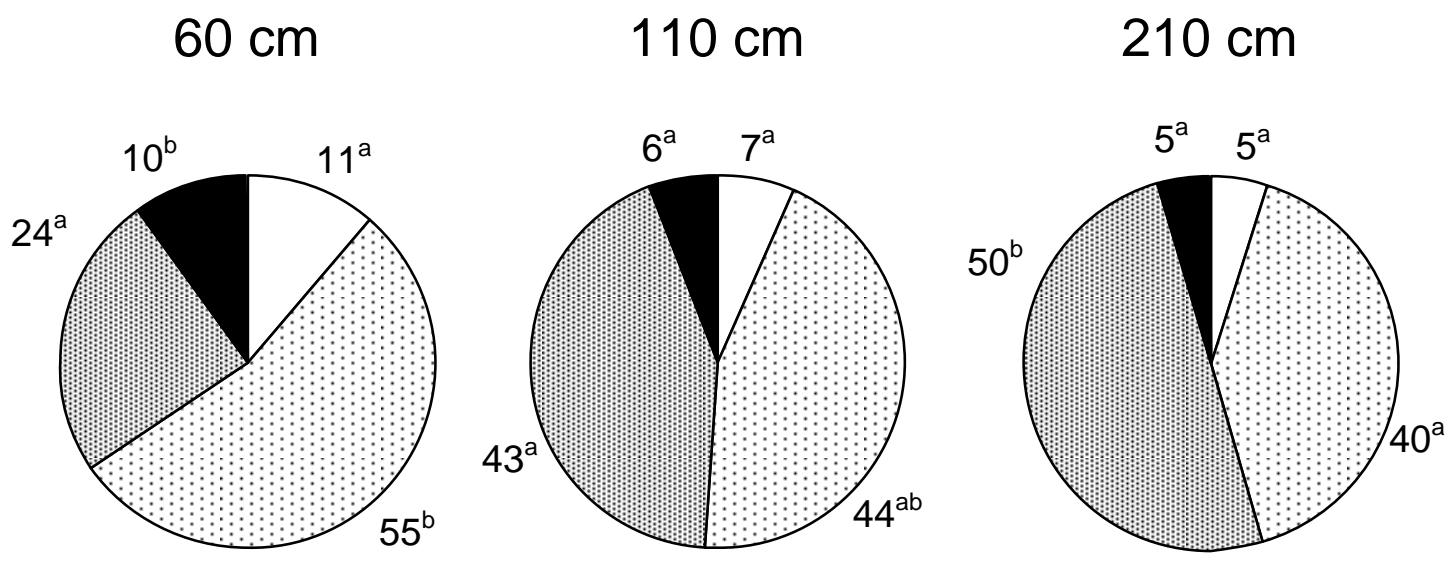

Area in \%

$\square$ White-grey volumes

Pale-brown volumes

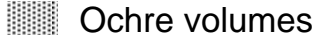

Black volumes 